There is thus some evidence that the incorporation of impurities during the deposition of DC magnetron sputtered tungsten films may account for their excellent barrier properties. However, the fact that these films tend to possess fewer microstructural defects than RF sputtered films may also be significant (12). More definitive studies will be necessary to elucidate the operative mechanism relevant to this phenomenon.

\section{Acknowledgements}

The author gratefully acknowledges the assistance of Linda Wagner who carried out most of the sputter depositions, Lillian Gulbrandsen who carried out the Auger depth profile analyses and Claire Hovland who furnished considerable support and encouragement in the completion of the manuscript.

This work was carried out while the author was employed at PerkinElmer, Physical Electronics Division, Mountain View, CA., U.S.A

\section{References}

1 M.-A. Nicolet, Thin Solid Films, 1978, 52, 415-443

2 T. S. Liu, W. R. Rodrigues de Miranda and P. R. Zipperlin, Solid State Technol., 1980, 23, 71-79

3 J. M. Harris, E. Lugujjo, S. U. Campisano, M.-A. Nicolet and R. Shima, J. Vac. Sci. Technol., 1975, 12, 524-527

4 R. S. Nowicki, J. M. Harris, M.-A. Nicolet and I. V. Mitchell, Thin Solid Films, 1978, 53, 195-205

5 C. R. Fuller, private communication

6 R. S. Nowicki, W. D. Buckley, W. D. MacKintosh and I. V. Mitchell, J. Vac. Sci. Technol., 1974, 11, 675-679

7 J. E. Baker, R. J. Blattner, S. Nadel, C. A. Evans, Jr. and R. S. Nowicki, Thin Solid Films, 1980, 69, 53-62

8 P. H. Holloway and C. C. Nelson, Thin Solid Films, 1976, 35, L13-L16

9 H. M. Dalal, M. Ghafghaichi, I. A. Kasprzak and H. Wimpfheimer, U.S Patent 4,215,156 (1980)

10 L. E. Davis, N. C. MacDonald, P. W. Palmberg, G. E. Riach and R. E. Weber, 'Handbook of Auger Electron Spectroscopy', 2nd edition, Physical Electronics Industries, Eden Prairie, MN., 1976

$11 \mathrm{~J}$. Stimmell, private communication

12 M.-A. Nicolet and M. Bartur, J. Vac. Sci. Technol., 1981, 19, 786-793

\title{
Low-Carat Gold Plating
}

\section{FUNDAMENTAL PROBLEMS EXPERIENCED WITH GOLD-SILVER SOLUTIONS}

When the price of gold made its relatively sudden rise from US $\$ 3.50$ to over $\$ 800$ in late 1979 /early 1980 , manufacturers involved in decorative gold plating made considerable efforts to find ways of reducing the amount of gold which they required. These efforts included attempts to reduce the amounts of gold electrodeposited onto base metal articles such as chains, rings, bracelets and pendants in the production of costume jewellery. Savings were sought in two major directions: (a) by reducing the gold thickness to a minimum consistent with the performance requirements of the products, and (b) by reducing the caratage of part of the gold deposit through alloy plating.

The problems which were then encountered are well illustrated in a paper read to the 1981 International Precious Metals Institute 5th Annual Conference by F. R. Mazzotta of Avon Products, Inc., Mansfield, MA.. Avon Products investigated the feasibility not only of reducing gold thickness, but also of changing in part from 22-23 carat to 12-14 carat gold by co-deposition of silver with gold. Some of the difficulties experienced in plating gold-silver alloys were similar to those reported by others in this connection and with the electrodeposition of alloys generally. The particular merit of Mazzotta's contribution, however, is the frankness with which these problems are described. It serves, in fact, as a sober reminder that alloy plating on a massproduction scale is still a very difficult operation requiring considerable technological back-up and resources.

Mazzotta's results on the effect of gold deposit thickness on porosity, and thus susceptibility to base metal corrosion, agree well with those of D. G. Foulke (Prod. Finish., 1967, 20, (12), 38-44) and A. A. Khan (Plating, 1969, 56, (12), 1374-1380). Thus, under production conditions using a normally prepared substrate surface and DC plating, a gold deposit thickness of 0.87 to $1.25 \mu \mathrm{m}$ ( 35 to 50 microinches) represents a threshold, below which an unacceptable level of porosity and substrate corrosion will normally occur.

A 12-14 carat binary gold-silver plating system was chosen partly because of its ready availability from suppliers, and partly because it seemed simple in operation in comparison with an alternative ternary system. It was also known that it had been used commercially in the eyeglass frame and watch case industries (often regarded as more technologically based than the costume jewellety industry).

Brass samples were rack-plated to a nominal specification of $0.87 \mu \mathrm{m}$ of 12-14 carat gold-silver alloy with a final deposit of $0.37 \mu \mathrm{m}$ of $22-23$ carat gold. Testing revealed the following fundamental problem areas:

(1) The two-layer gold deposit did not behave in the same manner as the $22-23$ carat gold coating in all corrosion tests. The former showed a more orange colour after accelerated corrosion testing in aqueous media

(2) When rack plating from the gold-silver solution, not only did sample position influence deposit thickness through variations in current density, but also caratage which was found to vary between 8 and 14 ( 35 to 58 weight per cent gold)

(3) If the gold content in the gold-silver underlayer dropped to below 50 per cent (12 carat) the corrosion and tarnish resistances of the finished products were adversely affected

(4) Apart from its dependence on current density the caratage of the gold-silver underlayer was markedly affected by changes in solution temperature, gold and silver concentrations, and by bath agitation (this latter effect is particularly marked in a heavilyworked bath). These observations closely mirror those made by R. E. Harr and A. G. Cafferty (Proc. Am. Electroplat. Soc., 1956 43, 67-69 and Met. Finish. , 1958, 56, 55-57) in early experiments on a similar bath

(5) Beta backscatter techniques were found unsuitable for consistent monitoring of deposit thicknesses, because of the variations in caratage. Microcoulometric analysis showed promise in this regard, but equipment availability, test duration and the need for skilled interpretation of data mitigated against its use.

It appears, therefore, that serious and fundamental problems must be overcome before satisfactory production results can be expected from this system. 